\title{
Desain Mainan Konstruksi Bertransformasi untuk Melatih Motorik Anak Usia 4 - 6 Tahun
}

\author{
Lia Nandika Wibisono dan Andhika Estiyono \\ Desain Produk Industri, Fakultas Arsitektur, Desain dan Perencanaan, Institut Teknologi Sepuluh Nopember (ITS) \\ e-mail: wibisononandika@gmail.com
}

\begin{abstract}
Abstrak-Usia prasekolah (4-6 tahun) merupakan tahapan usia dimana anak mengalami penyempurnaan perkembangan dalam berbagai aspek, salah satu nya adalah perkembangan motorik. Keterampilan motorik yang terbagi menjadi motorik kasar dan motorik halus, adalah sebuah tahapan perkembangan yang cukup kompleks dan berkesinambungan. Perkembangan motorik anak yang baik akan sangat berpengaruh pada perkembangan anak secara keseluruhan, karena keterampilan motorik memiliki kaitan erat dengan kemampuan interaksi sosial anak, kemandirian, serta kemampuan anak dalam menyesuaikan dengan lingkungan, terutama lingkungan sekolah bagi anak usia pra sekolah. Mainan sebagai sarana untuk membantu anak mencapai perkembangan yang utuh harus dipilih dengan menyesuaikan pada kebutuhan dan minat anak, tujuannya agar mainan dapat memberikan efek stimulasi yang tepat dan sesuai dengan tahapan perkembangan anak. Melalui proses observasi dan proses analisis tentang kegiatan harian anak pra sekolah yang berkaitan dengan keterampilan motorik, diketahui bahwa jenis permainan yang tepat untuk menstimulasi keterampilan motorik anak pra sekolah diantaranya adalah mainan konstruksi dan mainan tungganga (ride on toys). Masing-masing dari mainan tersebut memiliki peran dalam menstimulasi kemampuan motorik halus dan motorik kasar. Kombinasi dari kedua jenis permainan ini akan menghasilkan efek stimulasi motorik yang menyeluruh bagi anak prasekolah. Hal inilah yang mendasari penulis untuk merancang sebuah permainan konstruksi bertransformasi, yaitu mainan konstruksi yang dapat dibongkar pasang menjadi sebuah permainan yang memiliki bentuk serta fungsi baru. Target utama dari permainan dengan fungsi baru adalah ride on toys berupa balance bike dan scooter.
\end{abstract}

Kata Kunci-Kemampuan motorik, Mainan Kontruksi, Transformasi, Ride on toys

\section{PENDAHULUAN}

A NAK usia dini adalah anak yang berada pada rentang usia 0-6 tahun (Undang-Undang Sisdiknas tahun 2003), pada usia ini anak mengalami pertumbuhan dan perkembangan yang sangat pesat. Perkembangan pada anak usia dini merupakan sebuah perubahan yang terjadi secara bertahap dan terus berlangsung hingga mencapai usia tertentu. Perkembangan ini akan lebih teroptimalkan jika lingkungan tempat tumbuh kembang anak mendukung anak untuk bergerak bebas.

Untuk anak usia 4-6 tahun yang masuk kategori usia pra sekolah, perkembangan motorik merupakan salah satu aspek yang mengalami perkembangan sangat pesat. Hurlock (1998) mengatakan bahwa perkembangan motorik merupakan proses tumbuh kembang kemampuan gerak seorang anak melalui kegiatan pusat syaraf, urat syaraf, dan otot yang terkoordinasi. Perkembangan motorik anak terbagi mejadi motorik halus serta motorik kasar.
Perkembangan motorik yang optimal dapat memungkinkan seorang anak melakukan berbagai hal dengan lebih baik, antara lain dapat membangun kepercayaan diri, meningkatkan keterampilan sosio emosional, melatih kemandirian, pembentukan karakter serta konsep diri, termasuk di dalamnya pencapaian dalam hal akademis.

Optimalisasi perkembangan motorik anak pra sekolah dapat dilakukan melalui kegiatan bermain. Hal ini sesuai dengan apa yang dikemukakan oleh Freeman dan Munandar bahwa aktifitas bermain dapat membantu anak mencapai perkembangan yang utuh [1]. Melalui kegiatan bermain, anak tidak hanya dapat menghibur diri namun juga dapat dapat melakukan atau mempraktikkan keterampilan, memberikan ekspresi terhadap pemikiran, menjadi kreatif, serta mempersiapkan diri untuk berperan dan berperilaku dewasa. Bermain sebagai suatu aktivitas yang memberikan stimulasi dalam melatih kemampuan anak, memerlukan adanya perhatian khusus, terutama dalam proses pemilihan jenis permainan. Permainan yang dipilih harus menyesuaikan pada usia, minat dan perkembangan anak.

Adanya kebutuhan akan jenis permainan yang dapat memfasilitasi pertumbuhan motorik anak prasekolah secara menyeluruh, menghasilkan sebuah konsep perpaduan antara mainan konstruksi dan ride on toys berupa balance bike maupun scooter. Kedua jenis permainan tersebut dipilih arena masing-masing dari permainan tersebut sangat baik untuk menstimulasi motorik halus dan motorik kasar anak. Layaknya media belajar dan bermain pada umumnya, anak membutuhkan hal-hal yang dapat menimbulkan minat, ketertarikan, maupun antusiasmenya. Mainan konstruktif yang dapat dirakit menjadi bentuk mainan dengan fungsi baru diharapkan dapat menjadi daya tarik bagi anak untuk berkreasi, sekaligus juga dapat menjawab kebutuhan perkembangan motorik anak usia secara keseluruhan.

\section{METODE PENELITIAN}

\section{A. Tahap Pengumpulan Data}

1. Deep Interview

Pada tahap ini dilakukan pengambilan data primer maupun sekunder. Data primer diambil melalui deep interview dengan orang tua anak untuk mengetahui pertimbangan dan minat dalam memilih mainan anak. Hal ini bertujuan untuk mengetahui ragam mainan yang dimiliki, kebutuhan stimulus tumbuh kembang motorik serta daya beli konsumen.

2. Observasi Lapangan

Tahap pengambilan data berikutnya yakni melakukan observasi lapangan pada anak usia 5 tahun untuk mengetahui rincian aktivitas harian anak yang 
berkaitan dengan keterampilan motorik. Selanjutnya hasil observasi digunakan untuk menentukan bentuk transformasi ride on toys yang sesuai dengan kebutuhan dan minat anak.

\section{Affinity Diagram}

Metode berikutnya yaitu membuat affinity diagram, analisis menggunakan metode ini merupakan proses tindak lanjut dari metode - metode sebelumnya. Affinity diagram bertujuan untuk mengelompokkan masalah, fenomena maupun hal menarik yang ada didapat dari hasil pengumpulan data sebelumnya. Selanjutnya dari semua isu permasalahan yang didapatkan dikelompokkan sesuai kata kunci yang sesuai sehingga membantu dalam pembuatan konsep desain.

Tahap pengumpulan data pendukung lainnya adalah pengambilan data sekunder yakni literatur dari jurnal, majalah, artikel dari web resmi, dan studi sebelumnya yang berkaitan guna menunjang vaiditas data primer yang dilakukan sebelumnya.

\section{B. Eksplorasi Ide}

Ideasi Sketas - Hasil pengumpulan data sekunder dan primer diolah dengan melakukan ideasi sketsa untuk mencari gambaran umum bentuk transformasi secara umum sesuai konsep desain.

\section{Pemilihan Alternatif Desain}

Hasil eksplorasi ide selanjutnya dikerucutkan ke dalam beberapa alternatif desain, yang kemudian dilanjutkan dengan pemilihan alternatif desain final berdasarkan indikator yang sesuai dan mengacu pada hasil riset dan perancangan.

\section{Studi dan Analisis Desain}

Alternatif desain terpilih kemudian dikembangkan lebih detail dengan support studi dan analisis desain yang sesuai dengan konsep desain seperti aspek teknis, bentuk, dll.

\section{E. Pengembangan Desain}

\section{Studi Model}

Metode selanjutnya yakni melakukan studi mode 1:5 untuk mencari kesesuaian bentuk dan transformasi yang lebih kongkret sehingga dapat menghasilkan batasan konfigurasi bentuk.

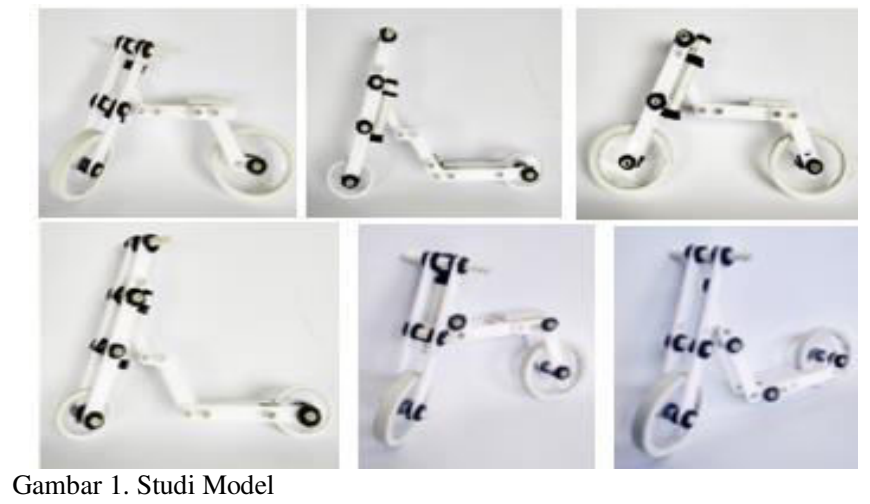

2. Digital Modelling
Alternatif desain terpilih selanjutnya disimulasikan dengan digital modelling untuk menemukan alternatif per part nya untuk menemukan desain akhir.

\section{F. Prototyping}

Desain akhir yang telah sesuai diwujudkan dalam bentuk prototype berskala 1:1. Namun karena keterbatasan kemampuan, waktu dan biaya, maka prototype dibuat tidak menggunakan material yang sebenarnya, seperti misalnya terdapat part yang harus dibuat menggunakan material plastik dengan teknik injection molding hanya dibuat dengan menggunakan cetak manual dengan material resin dan fiber glass.

G. Usability Testing

Tahap terakhir melakukan pengujian prototype menggunakan usability testing, yakni mencobakan kepada target user dalam hal ini anak - anak untuk mengetahui kekuatan, ketahanan beban dan kenyamanan.

\section{KONSEP DAN ANALISA}

\section{A. Konsep Desain}

Data-data, Ide maupun percobaan yang telah dilakukan selanjutnya diolah untuk menemukan konsep desain melalui brainstorming sebagai berikut :

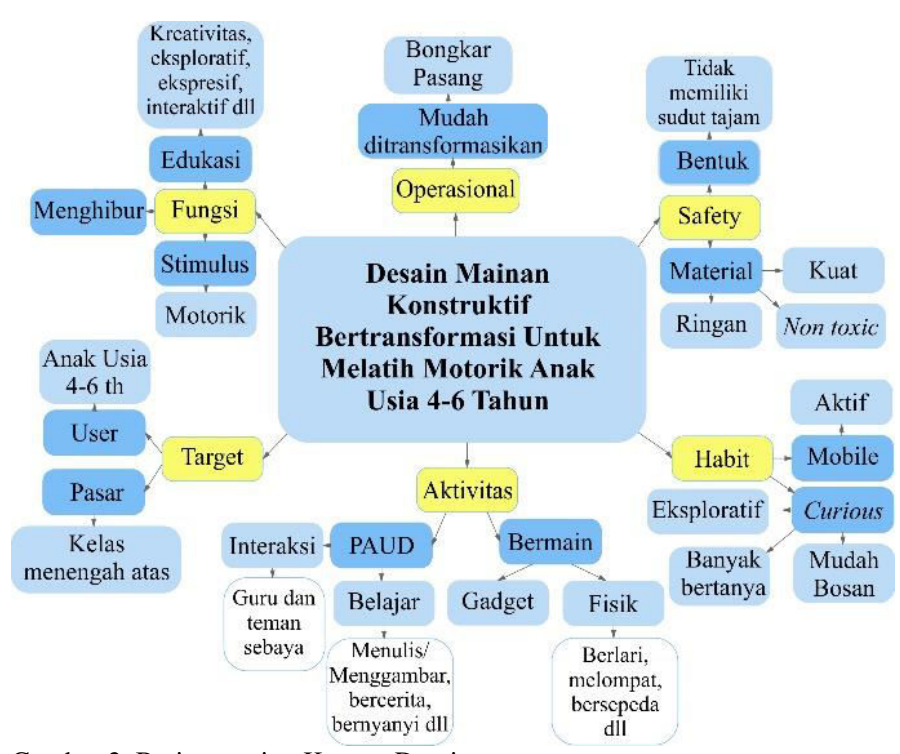

Gambar 2. Brainstorming Konsep Desain

Brainstorming di atas menghasilkan 3 kata kunci dalam konsep desain, antara lain :

\section{a. Fun Learning}

Menciptakan pola permainan yang tidak hanya menghibur namun juga dapat memberikan nilai edukasi bagi anak.

b. Knockdown

Permainan yang dapat dibongkar pasang dan diubah menjadi bentuk permainan baru yang lebih variatif.

c. Moveable

Mainan yang dapat mendorong anak untuk lebih bergerak aktif.

\section{B. Studi Gerak Motorik Anak}


Hasil dari observasi lapangan pada kegiatan harian anak prasekolah menunjukkan bahwa terdapat kompleksitas gerak motorik anak seiring dengan beragamnya aktivitas anak dan bertambaknya usia. Selain itu observasi lapangan juga dilakukan untuk mengetahui kebutuhan-kebutuhan tersembunyi anak yang berkaitan dengan perkembangan motorik. Kebutuhan-kebutuhan ini akan dijadikan acuan dalam memilih jenis permainan yang tepat untuk anak prasekolah.

\begin{tabular}{|c|c|c|c|}
\hline Kategori & Aktivitas & Kebutuhan & Jenis Permainan \\
\hline $\begin{array}{c}\text { Keterampilan } \\
\text { Motorik } \\
\text { Halus }\end{array}$ & $\begin{array}{l}\text { - } \text { Menggeng } \\
\text { gam } \\
\text { - Memutar } \\
\text { - Menarik } \\
\text { - Menempel }\end{array}$ & $\begin{array}{l}\text { Sarana bermain yang } \\
\text { d a p a t m e } 1 \text { a t i h } \\
\text { koordinasi gerak antara } \\
\text { mata dan tangan, } \\
\text { terutama otot-otot kecil } \\
\text { yang terdapat pada jari- } \\
\text { jari tangan }\end{array}$ & $\begin{array}{c}\text { Mainan } \\
\text { Konstruksi }\end{array}$ \\
\hline $\begin{array}{c}\text { Keterampilan } \\
\text { Motorik } \\
\text { Kasar }\end{array}$ & $\begin{array}{l}\text { - } \text { Berlari } \\
\text { - } \text { nenyeimba } \\
\text { tubuh } \\
\text { - Melempar } \\
\text { - Menendang } \\
\text { - Mendorong } \\
\text { - } \text { Melompat }\end{array}$ & $\begin{array}{l}\text { Sarana bermain yang } \\
\text { dapat menunjang } \\
\text { kontrol gerakan yang } \\
\text { melibatkan seluruh } \\
\text { tubuh, m e lat } \mathrm{i} \text { h } \\
\text { keseimbangan tubuh } \\
\text { serta melatih kekuatan } \\
\text { tangan dan kaki }\end{array}$ & - Sepeda \\
\hline
\end{tabular}

\section{Analisa Geometri}

Hasil dari eksplorasi bentuk rangka secara umum diolah dalam analisis geometri yakni mencari geometri dasar rangka utama berdasarkan titik kritis pada eksisting ride on toys berupa skuter dan sepeda.

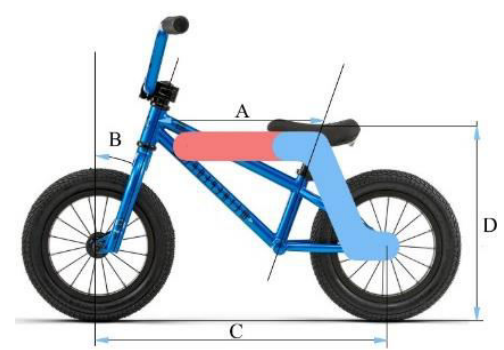

Gambar 3. Dasar Geometri pada Eksplorasi Rangka Sepeda

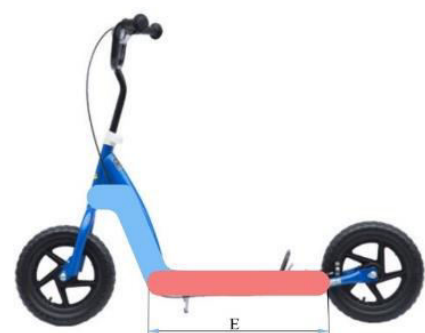

Gambar 4. Dasar Geometri pada Eksplorasi Rangka Skuter.

Dari analisa geometri diatas, dihasilkan dua konfigurasi rangka berbentuk sepeda dan skuter. Berikut ukuran dan titik kritis pembentuk rangka tersebut:

\begin{tabular}{|c|c|c|}
\hline Kode & Titik Kritis & $\begin{array}{c}\text { Ukuran } \\
\text { (mm) }\end{array}$ \\
\hline A & Jarak sadel dan handle bar & 395 \\
\hline B & Sudut kemiringan hed tube & $17^{\circ}$ \\
\hline C & Wheel base & 625 \\
\hline D & Ketinggian sadel & 450 \\
\hline E & Panjang rangka alas skuter & 200 \\
\hline
\end{tabular}

\section{HASIL DAN PEMBAHASAN}

\section{A. Pengembangan Desain}

Proses pengembangan desain dilakukan dengan mengembangkan desain tiap part, hal ini dikarenakan permainan yang dirangkai merupakan permainan konstruksi, sehingga agar dapat dirakit menjadi sebuat permainan ride on toys dibutuhkan beberapa jenis part yang berbeda. Berikut ini adalah pengembangan desain dari tiap part:

1. Axles Part

Axles Part adalah sebuah batangan berulir yang berfungsi sebagai poros pada sistem sambungan yang diterapkan pada mainan.

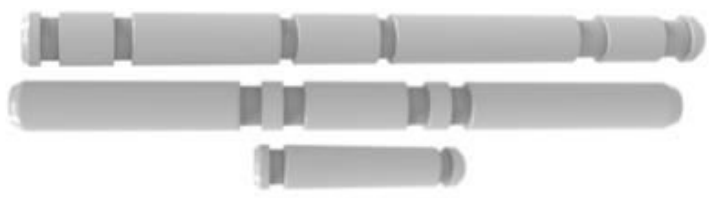

Gambar 5. Axles Part

2. Stopper Part

Stopper part merupakan bagian penunjang dari axles part, Stopper part ini nantinya berfungsi dengan cara mengganjal part yang akan dirakit.

Gambar 6. Stopper Part.

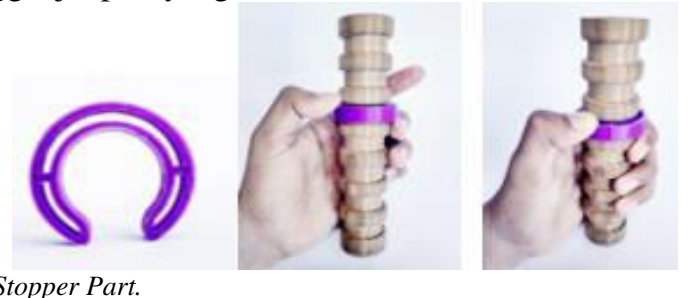

Kemudian setelah melakukan analisis lebih lanjut melalui skenario operasional, didapatkan evaluasi mengenai bentuk stopper part, agar menjadi lebih mudah saat dilepas.

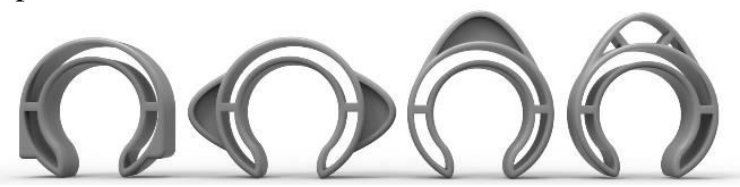

Gambar 7. Stopper Part Hasil Evaluasi Analisa Skenario Operasional.

3. Connector Part

Connector part merubakan bagian yang berfungsi untuk menghubungkan steering bar dengan frame utama.

Gambar 7. Connector Part.

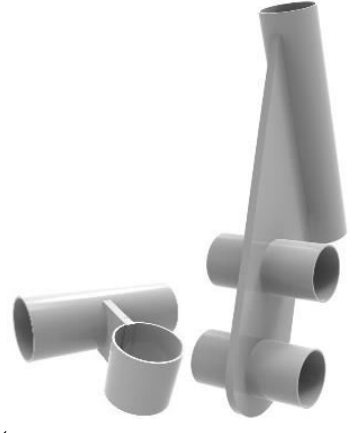

4. Frame Part 
Terdapat beberapa alternatif konfigurasi part rangka. Mulai dari alternatif 1 dan 2 yang hanya dapat dirangkai menjadi sepeda, hingga alternatif 3,4 dan 5 yang dapat dirangkai menjadi sepeda dan skuter. Jumlah part penyusun tiap alternatif juga berbeda-beda dan menjadi salah satu pertimbangan dalam pemilihan konfigurasi

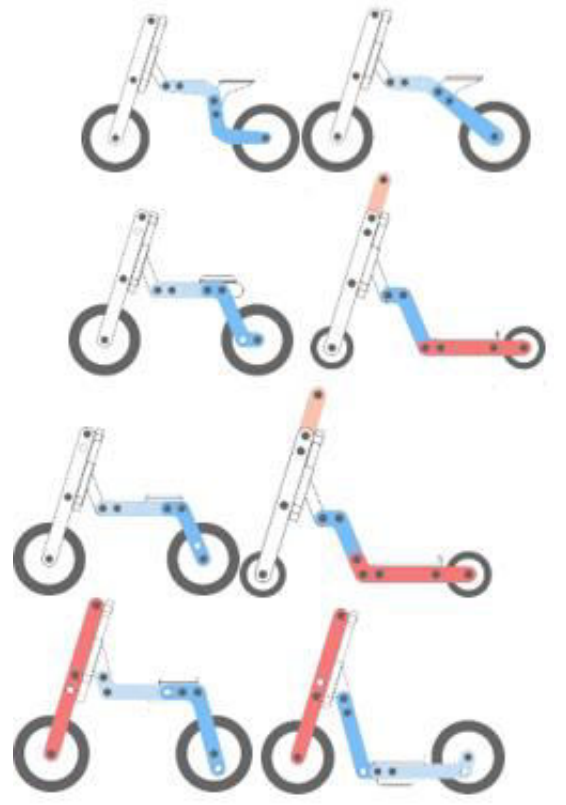

Gambar 8. Beberapa Alternatif Part Rangka.

\section{B. Analisis Material}

Analisis dilakukan dengan membandingkan tiap karakteristik material yang biasa digunakan pada mainan anak dengan kriteria yang dibutuhkan. Tiap part membutuhkan material dengan kriteria yang berbeda-beda. Untuk Connector part, material yang dipilih adalah alloy, dengan pertimbangan kekuatan, harga dan keringanan.

Sedangkan untuk frame part, material terpilihnya adalah plastik ABS, plastik dipilih karena mudah diproduksi menyesuaikan dengan bentuk desain serta cukup kuat. Karena menggunakan material plastik, frame part sedikit mengalami penyesuaian dengan mengurangi ketebalan dan menambahkan struktur penguat. Untuk menentukan bentuk struktur yang kuat dalam menahan beban, maka dilakukan sebuah simulasi digital menggunakan solidwork simulation express.

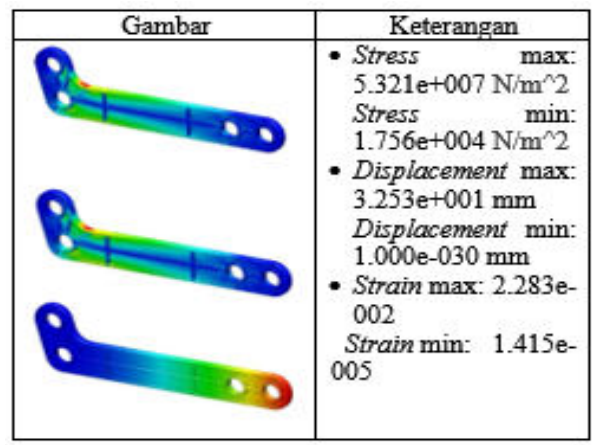

Dari data tersebut menjelaskan tentang stuktur frame yang telah terpilh berdasarkan proses simulasi. Berikut adalah bentuk frame yang telah ditambahkan struktur penguat

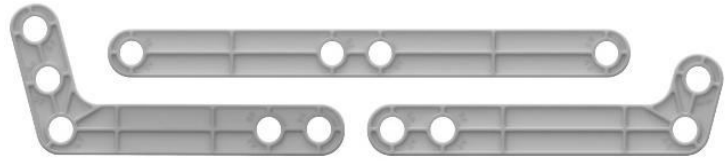

Gambar 9. Frame Part dengan struktur penguat C. Desain Akhir

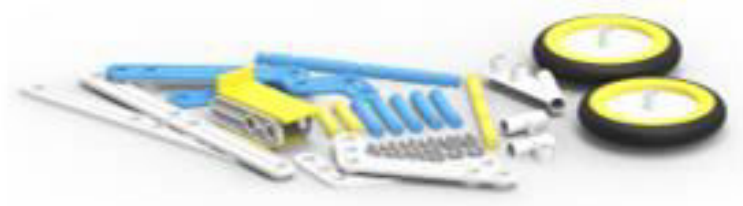

(a)

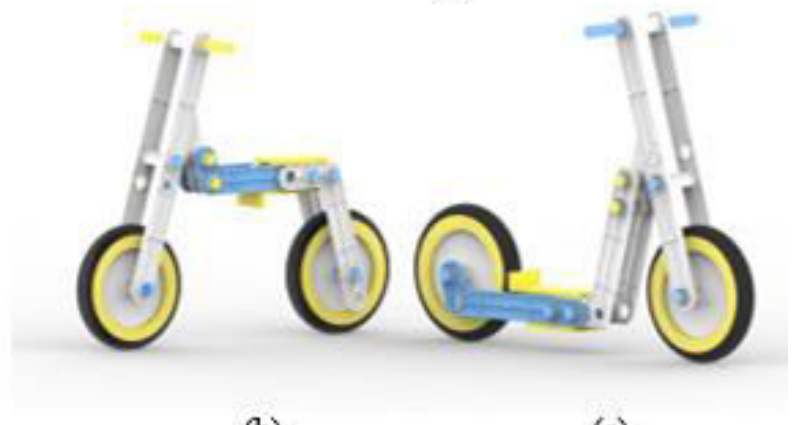

(b)

(c)

Gambar 10. Desain Akhir (a) Posisi Mainan saat Dibongkar (b) Balance Bike (c) Scooter

\section{KESIMPULAN}

Dalam mendesain mainan konstruksi bertransformasi sebagai sarana bermain pendukung pembelajaran gerak motorik anak prasekolah terdapat beberapa hal yang perlu dipertimbangkan antara lain :

1. Konstruksi rangka bodi utama harus kokoh sehingga dibutuhkan material dengan struktur yang kuat dan rigid.

2. Mengembangkan bentuk tiap part, terutama frame part agar dapat ditransformasikan menjadi mainan dengan fungsi yang lebih bervariasi.

3. Penentuan ukuran tiap part harus benar-benar tepat dan presisi, karena akan berpengaruh pada kemudahan proses perakitan serta kekuatan.

\section{DAFTAR PUSTAKA}

[1]

J. Freeman and U. Munandar, Cerdas Dan Cemerlang. Jakarta: Gramedia, 2001. 